\title{
Developing the concept of caring in nursing education
}

\author{
Maryam Salehian ${ }^{1}$, Abbas Heydari², Hossein Karimi Moonaghi ${ }^{3}$, Nahid Aghebati ${ }^{4}$
}

${ }^{1}$ Ph.D. Student in Nursing, School of Nursing and Midwifery, Mashhad University of Medical Sciences, Mashhad, Iran

${ }^{2}$ Ph.D. of Nursing, Professor, Department of Medical-Surgical Nursing, School of Nursing and Midwifery, Mashhad University of Medical Sciences, Mashhad, Iran

${ }^{3}$ Ph.D. of Nursing, Associate Professor, A- Evidence- Based Caring Center, B- Department of Medical-surgical Nursing, School of Nursing and Midwifery, and C- Department of Medical Education, Faculty of Medicine, Mashhad University of Medical Sciences, Mashhad, Iran

${ }^{4}$ Ph.D. of Nursing, Assistant Professor, Department of Medical-Surgical Nursing, Faculty of Nursing, Mashhad University of Medical Sciences, Mashhad, Iran

\section{Type of article: Original}

\begin{abstract}
Background: Caring is a value-based concept in the nursing field and in education. Exact understanding of caring in education and developing this concept in nursing will result in the evolution of the position of nursing science and profession.

Aim: The aim of this study was to attempt to develop the concept of caring in nursing education.

Methods: This qualitative study was conducted in 2016 using directed content analysis. Participants were thirteen subjects (6 instructors and 7 senior and junior nursing students) who were selected using purposeful sampling method. Research environment was the Faculty of Nursing and Midwifery in Mashhad. Data collection method was semi-structured interviews for thirty to ninety minutes and sampling continued until data saturation. Interviews were conducted in Persian language and they were immediately transcribed and analyzed using MAXDA10 software. The text of interviews was reviewed several times. First, open codes were extracted, and after several reviews based on similarity in meaning, they were classified into subcategories and finally, similar subcategories were placed in main classes based on meaning.

Results: Results of this study led to the identification of four themes: 1, ethical and religious commitment, 2, development of knowing and cultural sensitivity, 3, soft assertion, 4, clear describing of objectives, expectations, and educational rules for students.

Conclusion: Results of this study showed that the cultural and religious background of instructors affects their interaction with students. Instructors' commitment and compliance to values in interacting with students and other educational colleagues has an origin beyond ethical and human subjects and it is originated from their religious education and training.
\end{abstract}

Keywords: Caring Concept; Nursing Education; Development of Concept; Directed Content Analysis

\section{Introduction}

In recent decades, we have witnessed the evolution of concept analysis methods in nursing, the result of which has been the development of concept analysis techniques and promotion of their role in development of science. Rodgers \& Knafl (1) emphasized the necessity to propose new methods or redefinition of concept-based research methods. Their attempt resulted in the proposition of developing concept and its methodology in nursing; in addition, it was emphasized that concept analysis methods provide a basis to knowing how to advance a concept. Developing concept has been introduced as a step beyond concept analysis (determining the status of concept in

\section{Corresponding author:}

Professor Dr. Abbas Heydari, Department of Medical-Surgical Nursing, School of Nursing and Midwifery, Mashhad University of Medical Sciences, Mashhad, Iran. Tel: +98.5138591513, Email: HeidaryA@mums.ac.ir

Received: September 14, 2016, Accepted: November 14, 2016, Published: May 2017

iThenticate screening: November 12, 2016, English editing: May 10, 2017, Quality control: May 16, 2017

(C) 2017 The Authors. This is an open access article under the terms of the Creative Commons Attribution-NonCommercialNoDerivs License, which permits use and distribution in any medium, provided the original work is properly cited, the use is non-commercial and no modifications or adaptations are made. 
science) to develop concept-driven research, a clear explanation of concepts under study, and a special method to promote concept and create new knowledge (1-3). Developing concept, points to specific processing of conceptual semantic units and exact tagging of dimensions of concept. In terms of methodology, concept development is conducted via continuous implementation of qualitative and concept-driven research to recognize semantic gaps and deficits (2-4). Results of investigating caring concept analysis in nursing education show that caring in nursing education is considered as a teaching-learning process, which is based on mutual instructor-student relationships, and based on moral and human principles (5-12). In caring-based interaction, the instructor and student's actions and feelings are considered equally (9-13). Realization of this caring interaction requires a supportive and safe environment and free expression of beliefs $(6,14-16)$. In addition, compassion (17-21) and flexibility $(6,17,22-25)$ are recognized as some teaching strategies to realize a caring environment in nursing education. The product of this caring strategy in the teaching-learning process is internalization of caring values, self-esteem acquisition, moving forward and evolving the move $(7,11,22,23)$. Although the antecedent dimensions, characteristics and outcomes of caring in nursing education are reflected in numerous studies, there are still doubts found in the antecedent dimension and the characteristic of concept. In antecedent dimension, religious grounds and their effect on the way of instructor-student teaching, interactions are questioned; in addition, features like compassion and flexibility in educational relations accompany the consideration of lack of supplying or realization of teaching objectives. In fact, religious grounds of professors and boundaries of teaching rules as well as compassion and flexibility should be clarified as some dimensions of caring in the caring environment. Therefore, this study was conducted to answer some semantic ambiguities and deficits of concept and to clarify more dimensions of it, a study was conducted with the aim of developing a caring concept in nursing education.

\section{Material and Methods}

This study was a directed content analysis conducted in 2016 (26). Purposeful sampling was used in this study. Participants willing to interview were instructors with a teaching experience of at least two semesters of theoretical or clinical teaching $(n=6)$, and junior and senior students $(n=7)$. Sampling continued until data saturation. Research environment was the Faculty of Nursing and Midwifery in Mashhad. Data collection was conducted using semistructured interviews. Questions were designed in line with subjects' experience in terms of interaction in teachinglearning process. For instance, questions asked from instructors were:

1) Please explain one of your teaching sessions in theory or training classes.

2) How do your cultural or religious backgrounds affect your interaction with students or colleagues?

3) How do you interact with students to prevent any damage to teaching boundaries and rules with good caring behavior?

In addition, questions asked from nursing students were:

1) Describe one of your training or theory classes related to your caring instructors.

2) Describe one of your training or theory sessions where your instructor has had non-caring behavior with you or your friends.

In addition, alongside the above-mentioned questions, probing questions were used by the author to further enrich data. The author attempted to use participants' expressions relying on their experiences like other qualitative studies, and to prevent personal analysis and comments. Interviews lasted for thirty to ninety minutes. First, research objectives, interview method, and people's right to participate in or reject the study were explained to participants. Then, oral informed consent was obtained from them. Interviews were conducted in Persian language and they were immediately transcribed and analyzed using MAXDA10 software. All interviews were recorded, transcribed and investigated carefully. Data were analyzed using directed qualitative content analysis. This method is used when the available theory or previous research in this field is incomplete or more description of the phenomenon is beneficial. In this method, the researcher determines key concepts or variables as primary coding classes using available theories or previous studies (Table 1). The author reviewed and studied the text of interviews several times considering the selection of directed quality content analysis to obtain mentioned questions and ambiguities. Extracted open codes were placed in subcategories proportional to each gap and question, and finally, similar subcategories were placed in main categories. At the end, main categories were sorted with subcategories, open codes extracted from the text of interviews for final reporting. To approve the credibility, long-term involvement, data integration, data collection, field notes, manuscripts and recorded materials, supervisor's reviews and revisions and continuous comparison of data were used. Dependency that reflects data stability and duration was also considered. To this purpose, the author used external reviews via complementary comments of colleagues and reviewing manuscripts of participants. Validity of findings was determined by presenting reports, manuscripts and notes to four faculty members of the nursing department. In this study, confidentiality of information and obtaining 
informed consent for interviews and recording them were observed. Having the right to leave the study at any time was among ethical considerations observed.

Table 1. A sample of designed code sheet to reduce meaning units into sub-categories

\begin{tabular}{|l|l|l|}
\hline Subcategory & Open codes & Meaning unit \\
\hline $\begin{array}{l}\text { The effect of } \\
\text { family on } \\
\text { respectful behavior } \\
\text { of instructor and } \\
\text { student }\end{array}$ & $\begin{array}{l}\text { Instructor's occupational } \\
\text { behavior being influenced } \\
\text { by religious background of } \\
\text { their family }\end{array}$ & $\begin{array}{l}\text { "My own cultural and religious background has a significant } \\
\text { impact. As I have grown up in a religious and Shi'a family, I } \\
\text { have learned many things from my religion authorities and I } \\
\text { have learned many things outside my teaching environment" } \\
\text { (Instructor 1) }\end{array}$ \\
\cline { 2 - 3 } & $\begin{array}{l}\text { Influence of the family on } \\
\text { instructors in having } \\
\text { respectful behavior toward } \\
\text { others }\end{array}$ & $\begin{array}{l}\text { "My parents, especially my father always remind me of } \\
\text { Qur'an ayahs because they have been teachers and they } \\
\text { always say that this world is a place to pass and many things } \\
\text { you encounter in your life are from yourself and perhaps you } \\
\text { may not always have good interaction with others. Always } \\
\text { remember that these deficits are perhaps from you rather } \\
\text { than the other person" (Instructor 2). }\end{array}$ \\
\cline { 2 - 3 } & $\begin{array}{l}\text { Instructors being influenced } \\
\text { by their fathers' } \\
\text { recommendations on the } \\
\text { necessity to respect various } \\
\text { religions }\end{array}$ & $\begin{array}{l}\text { "My father always tells me that I should respect other } \\
\text { religions. I have my own beliefs, but I always respect this } \\
\text { difference in religion and belief of students" (Instructor 3). }\end{array}$ \\
\cline { 2 - 3 } & $\begin{array}{l}\text { The effect of family } \\
\text { background on instructor's } \\
\text { occupational behavior }\end{array}$ & $\begin{array}{l}\text { "My family training, especially our religious beliefs have } \\
\text { had a significant effect on our occupational attitude and } \\
\text { behavior. I try to treat students and my colleagues the same } \\
\text { way as when I was being trained" (Instructor 4). }\end{array}$ \\
\hline
\end{tabular}

\section{Results}

In this section of the study, a total of thirteen subjects, including seven students and six faculty members, who were selected using purposeful sampling, were interviewed. Results of these interviews were classified into two major gaps, including (1) the role of the instructor's cultural and religious background on interactive behavior of instructors with students; and (2) the position of educational rules in caring interactions, in four major classes: ethical and religious commitment, development of knowing and cultural sensitivity, soft assertion, clear describing of objectives and expectations, and educational rules for students (Table 2).

Table 2. Extracted categories and sub-categories resulted from developing caring concept in nursing education

\begin{tabular}{|l|l|}
\hline Categories & Sub-categories \\
\hline $\begin{array}{l}\text { Religious and moral } \\
\text { commitment }\end{array}$ & $\begin{array}{l}\text { Influence of the family on instructors in respectful behavior toward others, } \\
\text { Instructor's try to practice religious behaviors when interacting with students, } \\
\text { Instructor's try to observe Islamic rules when interacting with students of the } \\
\text { opposite sex. }\end{array}$ \\
\hline $\begin{array}{l}\text { Respectful relationship with } \\
\text { students }\end{array}$ & $\begin{array}{l}\text { Respecting students with different cultures, Encouraging and supporting cultural } \\
\text { activity of the faculty members, Developing cultural understanding of students } \\
\text { in caring for patients. }\end{array}$ \\
\hline $\begin{array}{l}\text { Cultural knowing and } \\
\text { sensitivity }\end{array}$ & $\begin{array}{l}\text { Being assertive against unconventional behavior of students, Kindly behavior of } \\
\text { instructors with offending students. }\end{array}$ \\
\hline Soft assertion & $\begin{array}{l}\text { Informing students of occupational clothing in the educational environment, } \\
\text { Familiarizing students with the laws of the educational environment, }\end{array}$ \\
\hline $\begin{array}{l}\text { Clearly describing goals, } \\
\text { expectations and educational } \\
\text { requirements for students } \\
\text { study. }\end{array}$ \\
\hline
\end{tabular}




\subsection{Religious Commitment and Moral Obligation}

3.1.1. Influence of the family on instructors in respectful behavior toward others

One of the major factors that result in prevalence of caring behavior among faculty members is their commitment to values and religious-cultural principles they have learned from their families and have grown with them. Value system and attitude is the way of interacting with others and encountering various situations affected by religious and cultural teachings where the family, especially parents, have contributed in its formation. For example, a participant explains: "My own cultural and religious background has a significant effect on my teaching behavior. As I have grown up in a religious and Shi'a family, I have learned many things from my religion authorities and I have learned many things outside my teaching environment. For instance, our holy prophet says, 'When somebody teaches me something, I owe to them and teaching others has a reward of years of worshipping Allah'. And another thing I can remember is that, the zakat of science is to teach it" (Instructor 1).

3.1.2. Instructor's try to practice religious behaviors when interacting with students

One of the strong points of the interviewed instructor's caring behavior was their attempt to practice those behaviors for which they have invited and ordered students. Practicing caring behavior is probably the most important factor that affects students' role modeling. "It is very difficult for me to talk about these beliefs. Although it is difficult for me, when it is Tasoo'a or Ashoora, I always mention some points about it. But, it is very difficult for me to talk about it. I always think that I wish these were not just mottos. For example, I say that you are not allowed to talk about great issues. You can talk to the extent that you practice it" (Instructor 4). "One point was their high level of knowledge. That is, they were at a high level in their own field, as well as their moral and religious knowledge. They tried to show us moral behavior in practice" (Student 1).

3.1.3. Instructor's try to observe Islamic rules when interacting with students of the opposite sex

One of the moral and religious characteristics of interviewed instructors was their commitment in observing religious affairs and privacy when interacting with students of the opposite sex. Instructors attempted to observe the relationship boundaries based on their religion while creating a mutual and active interaction and performing their tasks, and their teaching and consulting responsibilities. Another consideration among instructors that shows their moral and religious commitment, was their attempt to observe moral and religious boundaries when interacting with male and female students in the class. Instructors attempted to provide a relation based on respect towards students of the opposite sex with genteel and fair behavior while creating a peaceful and tensionless environment."By the way, we have religious boundaries to interact with people of the opposite sex. We should observe them according to our situation and age and we should teach students to be observant. Honestly, I always emphasize that students should have a respectful outlook towards the opposite sex and they should have an occupational relationship with them" (Instructor 6).

3.1.4. Respectful relationship with students

Respect in educational interactions is probably the most repeated concept noticed by instructors and students. Although creating and importance of mutual relation based on respect is mentioned by instructors and students among the features of caring concept, it should be noted that, as instructors stress, this interaction based on respect is the result of being trained in a religious context and instructors' commitment in employing religious teachings in social and occupational interactions. "The highest mission of the holy prophet is morality. For me, morality is when the student enters, I stand up for them as an instructor or consultant. I respect them and treat them with open arms. Invite them to my room" (Instructor 3). "They tried to show us moral behavior in practice. Another point is that they respect students and in the wards and classes they always respect us and they do not allow others to disrespect us" (Student 2). From the quotes of participants, it can be concluded that although these mentioned caring behaviors are rooted in moral issues, instructors' commitment to these behaviors is resulted from their training and growth in a cultural background and religious society.

\subsection{Cultural Knowing and Sensitivity}

The dynamic process of education is always influenced by cultural and social processes. Therefore, knowing and considering the different cultural needs of people has been considered as the major pillar of educational programs to give them services in the name of cultural competency. Findings of the present study verify the necessity to pay heed to these cultural competencies.

\subsubsection{Respecting students with different cultures}

Considering that leading universities attract and accept students from various subcultures from around Iran, and instructors are on the front line of interacting with them, instructors are required to view things void of prejudice and judgment towards students with various cultures. "One of the important issues for me is to respect various religions. For example, I have had a Sunni student who used to go to say noon and evening prayers. I paid attention to the positive point of saying prayers on time and I told the student, 'good for you for saying your prayers on time'. My 
father always tells me that I should respect other religions. I have my own beliefs, but I always respect this difference in religion and belief of students" (Instructor 5).

\subsubsection{Encouraging and supporting cultural activity of the faculty members}

Presence of committed and thoughtful instructors is required to train expert and committed students. Raising religious and cultural awareness of instructors has been known to be an important strategy in maintaining religious and cultural values of the country. "I have been attending Qur'an competitions for several years. I go independently from the instructors' science domain outside of faculty hours, and the faculty knows nothing about it. On two occasions, I even won the first rank in the competition of universities (Instructor 3).

\subsubsection{Developing cultural understanding of students in caring patients}

The result of supporting cultural activities of instructors and emphasizing development of respectful interaction of instructors with students in various cultures will lead to training students with cultural understanding in caring patients. Creating awareness and knowledge in students and practicing to achieve skills in treating patients of various cultures are of major and critical tasks of nursing instructors. "As nursing instructors, we practiced working with patients of various cultures and respecting all patients. And you should use their own language. For example, once I told my students that if I ask a villager whether they had defecation they would not understand, because it is not found in their culture. Rather, I should ask them whether their stomach worked. And this type of speaking is not disrespectful and it is a kind of respect for their culture. It means that you are talking to them with their own language to make them understand you" (Instructor 4).

\subsection{Soft Assertion}

Soft assertion includes measures taken by the instructors to create and maintain a caring atmosphere in the educational environment. These measures can be described as follows.

\subsubsection{Being assertive against unconventional behavior of students}

Improper sentiment and repeated appeasement of programmed decisions can damage instructors' assertion and influence. Inappropriate jokes also threaten the relation boundaries between instructors and students. "If we create an intimate environment such that the students think that there are no boundaries between instructors and students, it is too bad and we should not allow this to happen. And maybe it is required to treat students with our behavior and nonverbal reactions in various situations. It is difficult to use words. In the form of a simple frowning, a special facial expression, not smiling, simple frowning when they do something wrong, not changing your words. This is very important. For example, when you set some rules you should not change them. This creates boundaries and if you have extra flexibility, you will mislead them" (Instructor 1). "They emphasized to be on time in the morning. All students should be on the ward before 7:45 a.m. And that they were never late. They were very sensitive towards this" (Student 7). "When teaching, they were very serious and never allowed students to mislead discussion. At the break, they allowed students to comment" (Student 5).

\subsubsection{Kindly behavior of instructors with offending students}

Having a lifeless environment in the class and lack of flexibility in educational programs will damage instructorstudent interaction and on the other hand, extra kindness and lack of instructor's assertion in the class will result in chaos and ruin the respectful relation. Therefore, instructors' awareness and management in creating balance in educational interactions with students minimizes those threats."I had another class where the students were very naughty and they were notorious for this. They made me tired in the class and although I warned them and said that I would kick them out of the class, I did not know what to do with them in the ward. Then, I realized that treating these students, needs some tricks. That is, I realized that while observing disciplines as an instructor, we should be more caring when treating this group. I became kinder towards them and I tried to approach them. Then I found that they got along better with this method" (Instructor 5).

\subsection{Clearly Describing Goals, Expectations and Educational Requirements for Students}

Clear expression of educational requirements and expectations, is perhaps one of the most important features of caring in education that is neglected in most cases. This can be described in the following three subclasses.

3.4.1. Informing students of occupational clothing in educational environment

Observing occupational clothing will provide the possibility of appropriate educational activities and ease and peace in the educational environment while protecting human values and professional identity of students. Therefore, familiarizing students with rules and regulations and the type of occupational clothing in the educational environment are of authorities' responsibilities. "I have frequently asserted that students' wearing makeup is against occupational ethics. I heard one of the patients say that this nurse is such an atheist. A sprinkle splashed on her face. She washed herself for thirty minutes and then she wore makeup to come to the class" (Instructor 2). 


\subsubsection{Familiarizing students with the laws of educational environment}

Teaching students' regular and timely presence in an educational environment and emphasizing the observation of customs of attending classes and instructors' presence as well as patients' beds are considered as caring issues in educational environments. "I go to a training environment. Here, students should be present at 7:30 a.m. The very first day, I tell them that they should be present there exactly at 7:30. A nurse, who does not consider their timely work hour, would not become a real nurse. The first feature of successful people is their being on-time and therefore I sometimes berate them for this, because they should learn discipline" (Instructor 1).

\subsubsection{Familiarizing students of educational goals end expectations in their field of study}

Creating knowledge and giving awareness to students relative to educational objectives and expectations will facilitate monitoring and assessment of educational function and development of students, and make them focused while directing educational activities correctly. "I first should mention a major rule for them. I explain to them the reason of everything and for example, I ask them to make a pamphlet or educational movie and I explain the reason for them. For example, I say, we are following a developing career" (Instructor 4).

\section{Discussion}

Results of qualitative content analysis related to instructors and students' experiences of caring behavior in Mashhad, resulted in four main classes, including: ethical and religious commitment, development of knowing and cultural sensitivity, soft assertion, and clear describing of objectives and expectations.

\subsection{Influence of the Family on Instructors in Respectful Behavior toward Others}

Respectful behavior of instructors with students is probably one of the major features of instructors' caring behavior. Regardles of respectful behaviors being moral and human, these behaviors are valued and noticed more when they are originated from religious and famly training of instructors. This issue, i.e. the effect of instructors' cultural and religious background on their way of interacting with others, especially students is shown clearly. However, the study by Ghadami et al. shows that according to students, instructors' commitment to religious principles has had a minor effect on their relation with students (27) and this is while the study by Ali-Asghar Pour et al. showed that in instructors' assessment by students, morality and spirituality of instructors has had the highest score among personal and characteristic indices (28). This clear contradiction requires reflection and it is necessary to analyze this issue in detail in a qualitative study and from mutual views of instructors and students. In addition, instructors' commitment for practicing caring behaviors and them inviting students to good deeds were other valuable points mentioned in the findings of this study. As instructors of this study asserted, this behavior originates from their religious teachings and instructors practicing caring behaviors was the condition of acceptance and being a role model among students. The concept of practicing caring behaviors was noticed in the study by Heshmati Nabavi (29). In the study by Heshmati, integration between speech and performance of nursing instructors was introduced as a factor of becoming a perfect model among nursing students (29). In this study, instructors' cultural and religious background has been considered as important in practicing caring behaviors. Respectful behavior of instructors toward students is recognized as other features of caring behaviors expected from instructors. Clark considers irrespectful behavior of instructors resulted form an unequal balance of power between instructor and students (30). Although he believes that removing dignity and boundaries between instructor and students will also result in chaos (30). In their study, Ali-Asghar Pour et al. expressed respect of instructors toward students as necessary and one of the indices of evaluating instructors by students (28). Clark states that respectful and positive behavior of instructors results in similar behaviors in students (30). In this study, another example of instructors' commitment to cultural and religious training was their consideration and attempt to observe religious rules when interacting with students of the opposite sex as well as their attempt to observe moral and religious rules in male-female relations in the classroom. These dimensions clarify the effect of cultural background and religious beliefs on instructors' interaction more than ever. In sum, it can be stated that although instructors' caring behavior has been emphasized in domestic and foreign studies, the importance of cultural and religious origin of these caring behaviors has not been considered much, or it has not been the objective of any study. Although mentioned behavioral features are accepted as moral and human standards, according to the author, the origin and purpose of caring acts and behaviors or religious backgrounds that encourage these behaviors are of higher status. However, the effect of family background and training background of the family extracted form religious teachings should be investigated more than ever.

\subsection{Cultural Knowing and Sensitivity}

The necessity to know values, beliefs and other social, cultural and religious factors in society has found its status in developing health and assisting behaviors (30). These sets of competencies are relevant in all pillars of educational activities and the importance of this fact is well acknowledged in the findings of this study. While authorities' 
support of instructors' cultural activities promotes the instructors' cultural attitude, its outcome will be training believing students who are committed to religious and cultural beliefs. Outcomes of this cultural process is students' cultural understanding in caring for patients and health development. In the study by Heidari et al., cultural caring being less significant in the curriculum of nursing as well as low level of cultural competency of clinical nurses are mentioned (31). No research was found on the importance of promoting cultural activities of instructors.

\subsection{Soft Assertion}

Instructors' assertion allows them to deal with students' wrong behaviors and prevent any damage to relational boundaries between them and students when necessary, while creating friendly relation based on human values and kindness with students. Using encouragement and discouragement strategies and maintaining the boundaries of joking and even non-verbal and coercive responses to students can be effective. In his study, Heshmati (2012) emphasized creating an intimate and at the same time an official relation between instructor and students (29). In this regard, Clark explains that legal and appropriate use of power by instructors in an educational environment is an effective factor in the performance of educational activities and on the other hand, inappropriate use of this power will result in disturbance in the learning process. In addition, extra kindness and removing boundaries between instructors and students will result in chaos in the classroom. Instructors' management in creating balance and timely use of encouragement and discouragement strategies, silence, smiling and joking can provide a fresh educational environment far from boredom, while supplying and realizing educational goals (30). Creating knowledge and familiarizing students with educational rules and regulations is probably the first step in caring. Knowing and knowledge is an introduction to practice and act. Notifying students of occupational clothing, rules and customs of attending scientific and official environments and even the type and bundaries of relation with students of the same and opposite sex facilitate the path to realize goals and expectations. By providing enough information for students, the message of caring is transferred to them and we can clearly express our expectations as instructors form expected attempts, efforts and abilities of students when encountering occupational and social challenges. Mazaheri et al. introduced sharing educational goals and expectations with students and notifying them of educational objectives and goals as instructors' effective educational behaviors (32). In terms of instructors' assertion, the study by Aultman et al. has considered the necessity to create balance between emotional involvement (caring) of instructors and controlling students from instructors' point of view. In the study by Aultman, according to the instructors participating in the study, emotions in the classroom (positive or negative) will result in their susceptibility, and burnout and waste time in the class. Therefore, they elected to maintain emotional and relational boundaries between themselves and the students (33).

\section{Conclusions}

Results of this study clarified more dimensions of a caring concept in nursing education. Results of the study showed that the cultural and religious background of professors affects their interaction with students. Instructors' commitment to values when interacting with students or other colleagues originate beyond moral and human issues, rather, it originates from their religious training and education. Findings of this study can create a new attitude toward a concept that will result in scientific and occupational promotion of this field.

\section{Acknowledgments:}

Authors of this study express their thanks to all participants who compassionately took time and attended this study. Research Deputy of Mashhad University of Medical Sciences is appreciated for their support in conducting this study at the Midwifery and Nursing School.

\section{Conflict of Interest:}

There is no conflict of interest to be declared.

\section{Authors' contributions:}

All authors contributed to this project and article equally. All authors read and approved the final manuscript.

\section{References:}

1) Rodgers BL, Knafl KA. Concept Development in Nursing: foundations, techniques and applications. ed F, editor. Philadelphia: W.B Saunders; 1993.

2) Hupcey JE, Penrod J, Morse JM, Mitchman C. An exploration and advancement of the concept of trust. J Adv Nurs. 2001; 36(2): 282-93. doi: 10.1046/j.1365-2648.2001.01970.x. PMID: 11580804.

3) Penrod J, Hupcey JE. Enhancing methodological clarity: principle-based concept analysis. J Adv Nurs. 2005; 50(4): 403-9. doi: 10.1111/j.1365-2648.2005.03405.x. PMID: 15842447. 
4) Hupcey JE, Penrod J. Concept advancement: Enhancing inductive validity. Res Theory Nurs Pract. 2003; 17(1): 19-30. doi: 10.1891/rtnp.17.1.19.53168. PMID: 12751883.

5) Beck CT. Caring within nursing education: A metasynthesis. J Nurs Educ. 2001; 40(3): 101-9. PMID: 11302537.

6) Boykin A, Schoenhofer S. Nursing as caring: A model for transforming practice. NLN Publ. 1993; (152549): i-xxxii, 1-108. PMID: 8367273.

7) Cohen JA. Caring perspectives in nursing education: liberation, transformation and meaning. J Adv Nurs. 1993; 18(4): 621-6. doi: 10.1046/j.1365-2648.1993.18040621.X. PMID: 8496510.

8) Fahrenwald NL, Bassett SD, Tschetter L, Carson PP, White L, Winterboer VJ. Teaching core nursing values. J Prof Nurs. 2005; 21(1): 46-51. doi: 10.1016/j.profnurs.2004.11.001. PMID: 15682160.

9) Gillespie M. Student-teacher connection in clinical nursing education. J Adv Nurs. 2002; 37(6): 566-76. doi: 10.1046/j.1365-2648.2002.02131.x. PMID: 11879421.

10) Kim M. A Caring Perspective on Teaching. The Journal of Yeoline Education. 2007; 5(1): 257-79.

11) MacNeil MS, Evans M. The Pedagogy of Caring in Nursing Education. International Journal for Human Caring. 2005; 9(4): 45-51.

12) Salehian M, Heydari A, Aghebati N, Karimi Moonaghi H, Mazloom SR. Principle-based concept analysis: Caring in nursing education. Electron Physician. 2016; 8(3): 2160-7. doi: 10.19082/2160. PMID: 27123225, PMCID: PMC4844483.

13) Gillespie M. Student-teacher connection: a place of possibility. J Adv Nurs. 2005; 52(2): 211-9. doi: 10.1111/j.1365-2648.2005.03581.x. PMID: 16164482.

14) Burger KG, Kramlich D, Malitas M, Page-Cutrara K, Whitfield-Harris L. Application of the symphonological approach to faculty-to-faculty incivility in nursing education. J Nurs Educ. 2014; 53(10): 563-8. doi: 10.3928/01484834-20140922-02. PMID: 25275989.

15) Lasiter S, Marchiondo L, Marchiondo K. Student narratives of faculty incivility. Nurs Outlook. 2012; 60(3): 121-6. doi: 10.1016/j.outlook.2011.06.001. PMID: 21840556.

16) Lewis S, Rogers M, Rahel N. Caring-human science philosophy in nursing education: Beyond the curriculum revolution. International Journal for Human Caring. 2006; 10(4): 31-8.

17) Barolia R. Caring in Nursing from an Islamic Perspective: A Gounded Theory Approach. 16th International Nursing Research Congress. 2005.

18) Herbst AM, Swengros DI, Kinney G. How to teach human caring: Nurse educator role in transformational learning for a large healthcare system. J Nurses Staff Dev. 2010; 26(4): E6-E11. doi: 10.1097/NND.0b013e3181b1ba55. PMID: 20683295.

19) McCance TV, McKenna HP, Boore JR. Caring: theoretical perspectives of relevance to nursing. J Adv Nurs. 1999; 30(6): 1388-95. doi: 10.1046/j.1365-2648.1999.01214.x. PMID: 10583650.

20) Solvoll BA, Heggen KM. Teaching and learning care-Exploring nursing students' clinical practice. Nurse Educ Today. 2010; 30(1): 73-7. doi: 10.1016/j.nedt.2009.06.003. PMID: 19581026.

21) Wiklund Gustin L, Wagner L. The butterfly effect of caring - clinical nursing teachers' understanding of self-compassion as a source to compassionate care. Scand J Caring Sci. 2013; 27(1): 175-83. doi: 10.1111/j.1471-6712.2012.01033.x. PMID: 22734628.

22) Burke LL, Williams MG. Celebrating a commitment to care: building concernful practices among practitioners. J Nurs Educ. 2011; 50(1): 51-4. doi: 10.3928/01484834-20101029-07. PMID: 21053855.

23) Story L, Butts JB. Compelling teaching with the four Cs: caring, comedy, creativity, and challenging. J Nurs Educ. 2010; 49(5): 291-4. doi: 10.3928/01484834-20100115-08. PMID: 20143753.

24) Wade GH, Kasper N. Nursing Students' Perceptions of Instructor Caring: An Instrument Based on Watson's Theory of Transpersonal Caring. J Nurs Educ. 2006; 45(5): 162-8. PMID: 16722498.

25) Wafaa GA. Caring and Effective Teaching Behavior of Clinical Nursing Instructors in Clinical Area as Perceived by Their Students. Journal of Education and Practice. 2012; 3(7): 15-26.

26) Hsieh HF, Shannon SE. Three approaches to qualitative content analysis. Qualitative health research. 2005; 15(9): 1277-88. doi: 10.1177/1049732305276687.

27) Ghadami A, Salehi B, Sajadi S, Naji H. Students' Points of View Regarding Effective Factors in Establishing Communication between Students and Faculty Members. Iranian Journal of Medical Education. 2007; 7(1): 149-54.

28) Aliasgharpour M, Monjamed Z, Bahrani N. Factors affecting students' evaluation of teachers: Comparing viewpoints of teachers and students. Iranian Journal of Medical Education. 2010; 10(2): 186-95. 
29) Heshmati Nabavi F, Vanaki Z, Mohammadi E. The Mechanisms to Attract Nurses' Parthnership in Clinical Education: Perspective of Managers, Nursing Educators, and Staff Nurses. Iranian Journal of Medical Education. 2012; 11(6): 554-68.

30) Clark C. Student perspectiveson faculty incivility in nursing education: An application of the concept of rankism. Nurs Outlook. 2008; 56(1): 4-8. doi: 10.1016/j.outlook.2007.08.003. PMID: 18237618.

31) Heidari M, Anooshe M, Azadarmaki T, Mohammadi E. Exploration of context of the cultural care education in Iran. Journal of Nursing Education. 2013; 1(2): 1-8.

32) Mazaheri E, Mohamadi R, Naseri R. Investigation the effective clinical teaching behaviors in the view of nursing students of Ardabil university of medical sciences. J Ardabil Univ Med Sci. 2010; 12(3): 56-62.

33) Aultman LP, Williams-Johnson MR, Schutz PA. Boundary dilemmas in teacher-student relationships: Struggling with "the line". Teaching and Teacher Education. 2009; 25(5): 636-46. doi: 10.1016/j.tate.2008.10.002. 